\title{
Review of: "Effect of tetracycline on nitrogen removal in Moving Bed Biofilm Reactor (MBBR) System"
}

\author{
ROUMI BHATTACHARYA
}

Potential competing interests: The author(s) declared that no potential competing interests exist.

This paper has exhaustive and compact explanation regarding the influence of TC on nitrogen removal as also on various bacterial species of the biofilm. The work is novel and informative and an multidisciplinary approach towards wastewater treatment as also the microbial and its genetic aspect. The experimental consideration in this work can be further expanded to include the effect of several other influencing parameters, as both nitrifying and denitrifying bacteria is sensitive towards $\mathrm{pH}$, temperature and other factors. The inhibitory effect of TC along with these parameters can be further studied. 